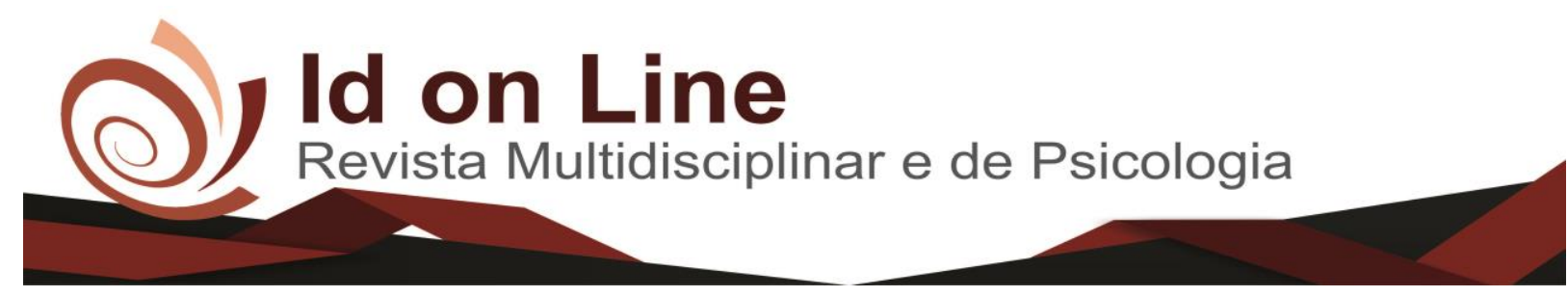

Comment

\title{
A Inclusão de Alunos com Altas Habilidades/Superdotação na Educação Básica: Um Desafio à Prática Pedagógica
}

Paula Renata Bezerra Xavier Sál

\begin{abstract}
Resumo: O presente artigo discute os princípios básicos da Educação Inclusiva, mas especificamente de alunos com Altas Habilidades/Superdotação, no tocante à necessidade e desafios para formar cidadãos. Esta pesquisa é de caráter bibliográfico e qualitativo e tem por objetivo analisar, conhecer e entender como a inclusão de alunos com Altas Habilidades e/ou Superdotação na Educação Básica se concretiza, pois acredita-se que toda criança deve ter o direito de estar inserida num programa educacional, independente de suas possibilidades de aprendizagens. Vale ressaltar que esse documento apresenta-se com a base teórica e metodológica em: Alencar (2007), Guenther (2000), Gardner (2000), Renzulli (2001), dentre outros. Observou-se no presente estudo que as crianças com Altas Habilidades/Superdotação, são aquelas que têm uma inteligência aguçada, sabem coisas demais precocemente e são taxadas como esquisitas e estranhas. Deste modo, entende-se, que a função da escola e, a função do professor frente à essa inclusão, é buscar compreender como esta se efetiva.
\end{abstract}

Palavras-chave: Inclusão Escolar. Altas Habilidades/Superdotação. Desafios da Prática.

\section{The Inclusion of Students with High Skills in Basic Education: A Challenge to the Teaching Practice}

\begin{abstract}
This article discusses the basic principles of Inclusive Education, but precisely of students with High Abilities / Giftedness, regarding the need and challenges to train citizens. This research is of a bibliographic and qualitative character and aims to analyze, to know and to understand how the inclusion of students with High Abilities and / or Giftedness in Basic Education becomes concrete, since it is believed that every child should have the right to be inserted in a educational program, regardless of their learning possibilities. It is worth noting that this document presents the theoretical and methodological basis in: Alencar (2007), Guenther (2000), Gardner (2000), Renzulli (2001), among others. It was observed in the present study that children with High Abilities / Giftedness are those who have a keen intelligence, know things too early and are taxed as weird and strange. In this way, it is understood that the role of the school and the role of the teacher in relation to this inclusion, is to try to understand how it is effective.
\end{abstract}

Keywords: School Inclusion. High Abilities / Giftedness. Challenges of Practice.

\section{Introdução}

Há muita discussão relativa a inclusão social na atualidade. Talvez por vivermos numa época onde o respeito à diversidade, bem como a garantia de direitos à participação social das pessoas, o respeito as suas especificidades (sejam: de gênero, étnicas, religiosas, sócio-

\footnotetext{
${ }^{1}$ Graduanda do curso de Pedagogia pela Faculdade de Ciências Humanas do Sertão Central -FACHUSC. Contato: djrafael369@ yahoo.com.br
} 
econômicas, físicas ou ainda psicológicas), têm surgido como uma questão ética, promovendo uma série de reivindicações sociais mais justas e mais igualitária.

Dessa forma, a temática da inclusão social agrega como pressuposto, a ideia de se considerar a diversidade humana, em seus diferentes tipos de atividades e suas diversas redes de relacionamentos, tende a estruturar-se para o atendimento "[...]às necessidades de cada cidadão, das maiorias às minorias, dos privilegiados aos marginalizados" (WERNECK, 1999, p. 108).

As instituições educacionais não podem resolver todos os problemas. Porém, pode acolher as pessoas com suas peculiaridades e diferenças. É importante que se consiga uma pedagogia sem medo do estranho, do diferente, do confronto com outro, como ele é. Aprendemos muitas vezes, muito mais com coisas diferentes daquelas do cotidiano.

Precisamos de uma pedagogia que seja uma nova forma de se relacionar com o conhecimento, com os alunos, com seus pais, com a comunidade, com os fracassos (com o fim deles), e que produza outros tipos humanos, menos dóceis e disciplinados. ABRAMOWICZ (1997, p. 89).

Por Inclusão escolar, vamos entender acolher todas as pessoas, sem exceção, em um sistema de ensino que seja independente, tratando com equidade as pessoas, seja qual for sua cor, classe social, condições físicas ou psicológicas.

O termo, normalmente, é associado à inclusão de pessoas no ambiente educacional, mas especificamente aquelas que possuem deficiência física ou mental. A motivação de tratar sobre a Inclusão Educacional de alunos com Altas Habilidades/Superdotação na Educação Básica surgiu de dúvidas e questionamentos de como se dá o ingresso desses alunos na rede de Ensino e de como apresentar propostas de ensino e aprendizagem que agucem cada vez mais o seu capital intelectual. Essa temática é resultante da necessidade de aprofundar o entendimento da trajetória da Educação Especial passa pela inclusão dos alunos com Altas Habilidades/Superdotação de fato são inclusos no processo ensino-aprendizagem, uma vez que estas crianças são vistas como quem sabe demais e não merece uma atenção diferenciada.

A inclusão não atende apenas as crianças com deficiência, mas também as que apresentam inteligência acima do esperado. Nesse contexto, necessita-se buscar alternativas de propostas pedagógicas, de atividades no âmbito escolar que propicie as crianças ou adolescentes superdotados vivências adequadas. Diante da problemática, questiona-se: Como incluir, de fato e de direito, os alunos com Altas Habilidades/Superdotadas na Educação Básica e qual o papel 
do professor neste processo? Vale ressaltar que o aporte teórico com esse estudo dialoga-se com: Alencar (2007), Guenther (2000), Gardner (2000), Joseph Renzulli (2001), dentre outros.

O artigo 208 da Constituição brasileira assegura que é dever do Estado garantir "atendimento educacional especializado aos alunos com deficiência, preferencialmente na rede regular de ensino". Tal condição, também consta no artigo 54 do ECA (Estatuto da Criança e do Adolescente). A lei também assegura às escolas, professores de ensino regular, que estejam preparados para apoiar alunos com necessidades especiais, a se integrarem nas classes convencionais. Uma criança com deficiência, não deve ter que buscar uma escola especializada.

A mesma possui esse direito de cursar em instituições comuns, assegurado. É dever da instituição educativa, elaborar e aplicar atividades, adequadas às necessidades dos alunos tidos como alunos com alguma deficiência ou necessidade educativa especial.

Entende-se que o aluno com deficiência deve ter o atendimento escolar especializado , assim como os alunos com Altas Habilidades e/ou Superdotação, desenvolvendo um trabalho especializado onde tenha estratégias e incentivos pedagógicos eficazes, que auxiliem na permanência e no sucesso desse aluno. É preciso reconhecimento da existência deste grupo, as suas necessidades para assim viabilizar propostas para atendê-los.

A Educação Inclusiva, de um modo geral, conduz a um campo de investigação abrangente, delimita-se a um trabalho de pesquisa, dando ênfase aos alunos com AH/SD que deverão ser acolhidos, como todas as outras pessoas, sem exceção, considerando que a inclusão é a capacidade de compreender e reconhecer o outro, de forma a que todos possam conviver e compartilhar. Ressalta-se que a inclusão se faz necessária em todas as dimensões sociais, partindo-se do princípio de que, é a escola, o lugar de formação e aperfeiçoamento dos indivíduos. Dessa forma, este estudo buscou conhecer de que forma os professores estão compreendendo a educação inclusiva, e propiciando uma vivência desta educação num contexto de prática educacional.

Entende-se que a educação inclusiva tem como objetivo analisar, conhecer e entender como os alunos com Altas Habilidades e/ou Superdotação na Educação Básica desenvolvem as suas potencialidades e capacidades, pois é muito necessário romper com os preconceitos e, aprender a conviver com as diferentes características humanas, como um valor e não, como dificuldades a serem sanadas. Esse parece ser o desafio.

Atuar como educador numa perspectiva inclusiva, significa uma chance que os professores têm de introduzir uma melhoria nas escolas. Garantir mais humanização e qualificar o acesso de todos às oportunidades educacionais e sociais. A vida de relacionamentos 
já é desafiante por si própria. Fazer da escola um ambiente receptivo para todos, é aceitar que todos somos diferentes em alguma dimensão.

Este artigo se apresenta sobre a forma de tópicos: o segundo discorre sobre a Educação Especial no Brasil e trata do surgimento da história da educação inclusiva, o terceiro retrata sobre o Conceito de Altas Habilidades/Superdotação, refere-se aqueles que têm uma inteligência aguçada, e o quarto aborda a formação do professor e a educação inclusiva no contexto das Altas Habilidades/Superdotação onde afirma que o professor deve apostar no aluno, e para isso é necessário conhecê-lo.

\section{A Educação Especial no Brasil: uma breve contextualização.}

No Brasil, a temática Altas Habilidades/Superdotação não é nova, já se passaram mais de 70 anos desde as primeiras abordagens. Helena Antipoff, quando no Brasil em 1929, deu início a pesquisas nessa área. A influência e o desenvolvimento das pesquisas desta autora foram fundamentais para a educação dos alunos com AH/SD (BRANCHER e FREITAS, 2011, p. 34).

Os dados históricos sobre as Diretrizes Curriculares da Educação Especial, implicou em currículos mais inclusivos. Ao longo da história são inúmeras foram as mudanças nas formas de organização do homem e de sua vida produtiva e material. Essas parecem ter definido uma série de transformações na educação do aluno da Educação Especial. Sabe-se que os trabalhos pioneiros sobre as AH/SD no Brasil, foram produzidos por Helena Antipoff.

Desde seus estudos até hoje, um considerável número de estudos e pesquisadores tem tentado conhecer melhor quem são os indivíduos com AH/SD e quais seriam as ferramentas e possibilidades para uma intervenção com estes.

Atualmente, o Ministério da Educação (2007) tem produzido significativas contribuições com relação às AH/SD. Conforme Alencar:

[...] Entre os fatores que têm contribuído para uma atenção crescente ao aluno que se destaca por potencial superior poder-se-ia citar o reconhecimento, que vem ocorrendo em distintos países, das vantagens para a sociedade que possibilita aos estudantes mais talentosos a realização de suas potencialidades. (ALENCAR, 2007, p.13). 
É notável que o superdotado presentemente ganha um certo destaque nos trabalhos e, consequentemente nas políticas governamentais, principalmente por conta da visibilidade que tem o conceito de altas habilidades. Segundo a autora, na contemporaneidade o domínio intelectual, sobretudo quando diz respeito às áreas tecnológicas, foi fator que levou a um novo olhar para as AH/SD. Alencar orienta:

[...] Ao longo das últimas décadas, os recursos naturais e o próprio capital financeiro vêm perdendo valor em relação aos recursos humanos. Especialmente os produtos de alta tecnologia tornaram-se fator importante na geração de riquezas. Esta nova fonte de riqueza depende diretamente do capital intelectual de mais elevado nível, que tem sido considerado, na atual sociedade do conhecimento, como o maior recurso a ser cultivado e aproveitado em favor da humanidade." (ALENCAR, 2007, p.13).

Entende-se, portanto que o atendimento a alunos com Altas Habilidades/Superdotados, no Brasil vem sendo uma preocupação de pesquisadores da área e do setor governamental, que se reflete no interesse na implementação de políticas públicas que favoreçam uma ação integrada. De maneira a aprimorar as práticas e a atuação dos professores, de modo a facilitar a aprendizagem dos alunos. Sendo assim, as Altas Habilidades/Superdotação estão incluídas na Educação Especial: sua primeira inserção foi em 1971 na Lei de Diretrizes e Bases da Educação Nacional (BRASIL, 1971).

Artigo $9^{\circ}$. De Acordo com o Ministério da Educação:

[...] Os alunos que apresentem deficiências, sejam físicas ou mentais, ou, os que se encontrem em atraso de qualquer natureza, quanto à idade regular de matrícula e, os superdotados, deverão receber um tratamento diferenciado, especial, de acordo com as normas fixadas pelos Conselhos competentes na área da Educação.(BRASIL, 1971).

Nota-se que muito se tem a descobrir/aprender sobre este tema, pois o mesmo é ainda hoje tão desafiador e ao mesmo tempo desconhecido por muitos, sendo considerado um "mito" para a maioria das pessoas, inclusive para os professores; que na grande maioria não tem conhecimento sobre o assunto, nem sobre como trabalhar com crianças que possuem um grau de desenvolvimento superior.

Neste contexto é possível afirmar que a inclusão de crianças com necessidades especiais está presente no dia a dia. Assim sendo, inserir alunos com déficits de toda ordem, seja ela grave ou menos grave no ensino regular, nada mais é do que garantir o direito de todos à educação - como afirma a Constituição. A Constituição Federal de 1988 e a lei de Diretrizes e 
Bases da Educação Nacional (LDBEN no 9394/96) estabelecem sobre os portadores de necessidades especiais que estes devem estudar, preferencialmente em escolas regulares, pois todos têm direito à educação. A Conferência Mundial sobre Educação para Todos (UNESCO, 1990) que foi realizada em Jomtien na Tailândia, adotou metas para melhoria da educação das crianças e jovens possuidores de necessidades especiais.

Diante disso a Declaração de Salamanca, que foi aprovada em 1994, em plena Conferência Mundial de Educação Especial, passou a contar com a inclusão dos alunos com necessidades educacionais especiais nas classes regulares como uma forma mais justa e avançada de prática democrática quanto às oportunidades educacionais. É pois, considerada uma das principais ferramentas mundiais de inclusão social. Esta declaração define que:

[...] Inclusão e participação são essenciais a dignidade humana e ao desfrutamento e exercício dos direitos humanos. Dentro do campo da educação, se reflete no desenvolvimento de estratégias que procuram promover à genuína equalização de oportunidades [...]. Ao mesmo tempo em que as escolas inclusivas proveem um ambiente que favorece a aquisição da equidade e igualdade de oportunidades, além de participação total. O seu sucesso requer um claro esforço, não somente por parte dos professores e dos profissionais na escola, mas por todos os que o rodeiam como colegas, pais, amigos, voluntários. (UNESCO, 1994, p. 5).

Nesse sentido, destaca-se que há uma acentuada orientação no sentido efetivo de contemplar a todos, orientando que o diferente passe a ser a norma e não a exceção nos sistemas destinados a atender tais necessidades. Considera-se que crianças e jovens cujas necessidades especiais perpassam de suas capacidades e dificuldades de aprendizagem, em algum momento de sua escolarização.

Segundo Sassaki, a inclusão "é um processo que contribui para um novo tipo de sociedade através de transformações, nos ambientes físicos (...) e na mentalidade de todas as pessoas" (2010, p. 40). Sendo assim afirma-se que o processo de inclusão ainda é frágil e falta o imaginário da aceitação do diferente, porém este, precisa quebrar parádigmas ultrapassando os muros da indiferença e, portanto aprender a conviver confirmando-se a inclusão de fato como ela deve ser tratada por todos os segmentos da sociedade.

\section{Conceituando Altas Habilidades/Superdotação.}

A Organização Mundial de Saúde, afirma que 3\% a 5\% da população, no Brasil, é portadora de habilidades diferenciadas ou altas habilidades, e segundo as Diretrizes Nacionais 
da Educação Especial, para a Educação Básica (BRASIL. MINISTÉRIO DA EDUCAÇÃO, 2001), o conceito de Altas Habilidades/Superdotação, tem sido adotado por alguns programas brasileiros, como forma de destacar crianças consideradas mais inteligentes, criativas e talentosas. Apresentam desempenho especialmente notável, bem como elevado potencial, tanto em aspectos isolados como em aspectos combinados: seja na capacidade intelectual geral, pensamento criativo ou produtivo, aptidão acadêmica específica, capacidade de liderança, capacidade psicomotora ou talento especial para as artes (SEESP - Secretaria de Educação Especial, 2006).

O Superdotado sempre foi visto com desconfiança pelo sistema educacional, somente nas últimas décadas o superdotado passou a receber mais atenção por parte das autoridades educacionais. $\mathrm{O}$ atendimento a essa parcela de da população, começa a ganhar visibilidade através de alguns programas específicos, os quais acabam encontrando dificuldades de ação devido aos preconceitos e estigmas que faz com esses alunos considerados diferentes, com potencial mais elevado, tornem-se quase que invisíveis, especialmente no contexto da sala de aula. $\mathrm{O}$ aluno superdotado por ser visto diferente apresenta também características diversas de acordo espaço em que ele está inserido. Assim coloca Guenther:

[...] Ao falar em 'crianças bem-dotadas e talentosas' não estamos falando em um grupo único, parecido, homogêneo e facilmente reconhecível em qualquer situação. Ao contrário, como todas as pessoas que existem, cada criança traz em si uma combinação essencial e substancialmente única de traços, características e atributos, oriundos não somente de sua própria constituição e plano genético, como também derivados e absorvidos de muitas fontes de influência presentes no ambiente a que é exposta, dentro dos vários grupos a que pertence. (GUENTHER, 2000, p. 44).

Vale notar a contribuição de Gardner (1995) quando afirma que essa modalidade tratase, não das altas habilidades somente, mas da manifestação das múltiplas formas de expressão da inteligências de um indivíduo, observando-se sua capacidade de resolver problemas ou de elaborar produtos, distanciando-se do conceito de que exista uma inteligência única e geral. Segundo o autor, o ser humano é dotado de inteligências múltiplas. E isso inclui as diversas dimensões a saber: dimensões linguística, espacial, lógico-matemática, naturalista, musical, interpessoal, cinestésico-corporal, e intrapessoal. Isso posto, entender-se-á que, as Altas Habilidades precisam ser consideradas, como alguma capacidade latente, que se encontra disponível ao alcance de todos os alunos. Estas formas de inteligência, já que se encontrariam em pleno processo de desenvolvimento, disponibilizando suas potencialidades. Conforme Landau afirma: 
[...] Quando uma criança superdotada percebe alguma coisa ou situação que os outros não notaram e ousa apontá-la, ela denota não apenas compreensão, mas também coragem de falar sobre algo novo, consciência de sua capacidade de percepção, bem como interesse e desejo de envolvimento com o assunto. No entanto ela somente adotará esse comportamento se o meio circundante a incitar para a aquisição de conhecimentos e permitir-lhe a manifestação das próprias ideias. (LANDAU, 1990, p. 13).

Reforça-se, portanto que parece não haver um conceito unânime de Altas Habilidades/Superdotação. Trata-se do Círculo dos Três Anéis (Figura 1) do psicólogo, pesquisador e educador norte-americano Joseph Renzulli, grande especialista mundial nesta área, nos orienta sobre a função decisiva da instituição educacional, em estimular o desenvolvimento das diversas capacidades, de forma criativa, em todos os seus educandos.

Segundo o modelo dos três anéis, todos os alunos que compõem esse grupo são os que apresentariam habilidades acima da média, quando relacionados aos seus pares, em uma ou algumas áreas da inteligência. Também apresentariam elevado nível de envolvimento com a tarefa.

Mostrando-se mais motivados e comprometidos. Essas três peculiaridades, demonstrariam que, através de uma interação dinâmica entre os três traços é que se observariam os elementos primordiais de uma ampliação da capacidade criativo-produtiva psicomotora. Renzulli conclui que, é a superdotação algo relativo. Seja ao tempo, seja às pessoas (não em todo o mundo) ou às circunstâncias. Portanto, os comportamentos superdotados se apresentariam mais em lugares determinados e em deterinadas pessoas, em dados momentos ou contextos. Para este autor, uma pessoa superdotada tem algumas características específicas e pode ser conhecida através dos seguintes comportamentos:

Nesse contexto pode-se afirmar que as altas habilidades ou superdotação, não necessariamente são como muitos ainda pensam, que seja uma espécie de dom, mas sim que agrega características e comportamentos que precisam e devem ser aperfeiçoados na interação com o mundo e portanto com o meio em que estes indivíduos estão inseridos. Portanto, estas pessoas são valiosíssimas tanto quanto todas as demais pessoas, e não podemos ignorá-las. É preciso oferecer mais oportunidades a todos e também a estes sujeitos com altas habilidades para que se cumpra o papel social.

Diante do exposto faz-se necessário apontar algumas características inerentes ao aluno superdotado. O artigo 5 , inciso III, da Resolução CNE/CEB, número 2 do ano de 2001, que estabelece as Diretrizes Nacionais para a Educação Especial na Educação Básica (Brasil, 2001), tem estabelecido que alunos com altas habilidades, mais especificamente aqueles com 
superdotação, apresentam maior facilidade de aprendizagem, o que os leva a dominar mais rapidamente procedimentos, conceitos e atitudes.

Em outra perspectiva, os Parâmetros Curriculares Nacionais, sobre Adaptações Curriculares, Saberes e Práticas da Inclusão (Brasil, 2004), material publicado pela Secretaria de Educação Especial do Ministério da Educação, observam a exist encia de determinados traços que são comuns aos superdotados, a saber: Alto grau de curiosidade; Atenção concentrada; Boa memória; Independência e autonomia; Criatividade e imaginação; Maior facilidade na aprendizagem; Um vocabulário mais avançado para a idade; Uma maior Facilidade nas interações interpessoais; Interesse por fontes de conhecimentos diversificadas; Originalidade para resolver problemas, dentre outros.

Cabe citar que testes e escalas psicométricas; questionários; entrevistas com a família e professores, e observação do comportamento, estão entre as possibilidades de identificação mais utilizadas para diagnosticar pessoas com Altas Habilidades/Superdotação, salientando que alguns destes testes já foram abolidos por serem defasados.

É necessário observar que escalas e outros instrumentos não fazem diagnósticos, mas são importantes ferramentas e se prestam para o rastreamento e suspeição, pois fornecem dados muito úteis para avaliação, pesquisa e intervenção. A identificação de alunos em situação de deficiência ou superdotação, requer a realização de uma sequência de procedimentos, que incluem etapas bem definidas com a utilização de instrumentos apropriados. É importante que a identificação seja um processo contínuo. Esta deve ser aprimorada por outras fontes de informação.

\section{A formação do professor e a educação inclusiva no contexto das Altas Habilidades/Superdotação.}

A inclusão escolar precisa levar em consideração a existência de uma pluralidade cultural, e da complexidade das redes de interação humana. Ela não deve se limitar à inserção daqueles alunos com deficiência na rede convencional de ensino. Deve-se pois, beneficiar todos os alunos, com ou sem deficiência, que são excluídos das escolas comuns do ensino mais tradicional, ministrado nas salas de aula do ensino normal/convencional, motivando em mudanças nos processos de ensino e de aprendizagem. Contudo as diferenças funcionam como 
um recurso gratuito, abundante e renovável... "O que é importante nas pessoas - e nas escolas - é o que é diferente, não o que é igual”. Assim diz Mantoan (2001) e ainda adverte que:

[...] Não lidar com as diferenças é não perceber a diversidade que nos cerca, nem os muitos aspectos em que somos diferentes uns dos outros e transmitir, explícita ou explicitamente, que as diferenças devem ser ocultadas, tratadas à parte." (MANTOAN, 2001, p.51).

Em contextos onde há inclusão, os alunos enriquecem-se ante a oportunidade de aprendizado na interação umas com as outras. Ocupam-se mais em cuidar umas das outras, bem como apropriam-se das atitudes, habilidades e domínio dos valores necessários, para garantia de uma adaptação mais inclusiva socialmente. Programas mais adequados na promoção da inclusão, funcionaria, em tese, para todos os alunos, de maneira mais ou menos eficiente. As atitudes positivas são uma habilidade importante para a vida na comunidade. Assim Mittler afirma:

[...] Inclusão e exclusão começam na sala de aula, são as experiências cotidianas das crianças nas salas de aula que definem a qualidade de sua participação e a gama total de experiências de aprendizagem oferecidas em uma escola. Do mesmo modo, são importantes as interações e as relações sociais que as crianças têm umas com as outras e com os outros membros da comunidade escolar. As formas através das quais as escolas promovem a inclusão e previnem a exclusão constituem o cerne da qualidade de viver e aprender experimentado por todas as crianças. (MITTLER, 2003, p.42).

O professor deve investir no aluno, e para isso é necessário conhecê-lo. Também é de essencial importância mobilizar esforços para habilitar todas as escolas para o atendimento dos alunos em qualquer comunidade, especialmente aqueles que têm sido excluídos das oportunidades educacionais. Não basta que todas as crianças especiais sejam matriculadas, é necessário criar condições para que estas possam manter-se na escola.

Dessa forma, os objetivos de uma ação didático-pedagógica juntos a alunos que possuam altas habilidades/superdotação, precisam alinhar-se com uma preparação para a independência e autonomia, desenvolver cada vez mais habilidades técnicas e sociais, inserir atividades de planejamento, oferecer estratégias que estimulem o posicionamento crítico e avaliativo, bem como implementar diferentes formas de pensamento. A estratégia da educação inclusiva, é levar os alunos a aprenderem na prática, envolvendo-se em situações do mundo real, que sejam mais significativas, onde suas habilidades serão desenvolvidas através da aplicação, estimulando-se o pensamento crítico e reflexivo. 
A Secretaria de Educação Especial - Ministério da Educação do Brasil, objetivando apoiar as instituições de ensino e, portanto subsidiar o trabalho dos docentes, implementou juntamente com as Secretarias de Educação em todos os estados brasileiros incluindo o Distrito Federal, e os Núcleos de Atividades de Altas Habilidades/Superdotação - NAAH/S, disponibilizando mais e especializados recursos didáticos - pedagógicos, investindo na formação continuada dos profissionais com competência técnica, de forma a atender com mais qualidade, os desafios acadêmicos e psico-emocionais de tais alunos. Seu maior objetivo é promover a formação e capacitação de professores e profissionais da educação para identificar e atender esses alunos.

É notável que os NAAH/S Núcleos de Atividades de Altas Habilidades/Superdotação atendem professores, alunos e a família no sentido de conhecê-los para melhor atendê-los e assim promover uma educação inclusiva e de qualidade.

Essa temática é pertinente e tem como foco levantar questionamentos e inquietar professores e educadores, assim como outros profissionais que se interessem pela mesma, entretanto esta, ainda tem uma longa jornada pela frente, visto que, para a maioria das pessoas é considerada como um "mito", inclusive para os professores, pois a grande maioria não tem conhecimento sobre o assunto, sequer como trabalhar com crianças que possuem um grau de desenvolvimento superior.

\section{Considerações Finais}

Diante do exposto, conclui-se que para o processo que vise a inclusão escolar, é necessário que haja uma transformação no sistema que venha a beneficiar toda e qualquer pessoa, levando em conta as potencialidades do sujeito e não mais as suas deficiências e limitações. O papel da escola é receber, ensinar e compartilhar junto aos professores os saberes, enquanto o aluno constitui-se como pessoa autônoma e preparam-se para o futuro com relações entre colegas, professores, funcionários, família e comunidade.

Faz-se notar a importância de entender que toda criança, independentemente de suas necessidades tenha o direito a participar de um ambiente que promova a inclusão e receber serviços especiais interagindo tanto quanto possível com os seus colegas.

A escola deve incumbir-se de uma educação centrada nos interesses e necessidades do educando. Promover uma convivência social saudável entre escola, família e comunidade. Estas 
precisam prever e prover na forma de organizar suas classes comuns, serviços de apoio psicopedagógico e outros auxílios especializados. É essencial que o aluno com necessidades especializadas para desenvolver altas habilidades/superdotação, avancem em seu próprio ritmo, explorando ao máximo seu potencial e competências, sem estar submetido a um conteúdo curricular que já domina; e que possa construir novos conhecimentos em convivência com parceiros de semelhante faixa etária, em um contexto normal de sala de aula. Não se deve impor ao aluno o trabalhar com conteúdos pouco desafiantes. É preciso mantê-los motivados para que se consiga facilitar sua aprendizagem.

Dessa forma, cabe a professores e pesquisadores, explorarmos este campo para melhor entendermos e assim fazermos a diferença no sentido de buscar melhorias no atendimento e no “aproveitamento" dessas "inteligências". Entretanto, na condição de docentes cabe a nós também, fazer duas grandes inferências: precisamos urgentemente de seminários, eventos, grupos de estudo, dentre outros, para que os estudiosos das AH/SD consigam delimitar as necessidades e perspectivas de atuação, e precisamos atuar na formação continuada de professores, entendendo essa como um processo amplo que deve iniciar dentro das escolas. Enfim, entender a inclusão como um processo implica uma visão voltada para o futuro, sendo que a inserção do aluno com necessidades especiais no mercado de trabalho é coroamento desse processo. Só assim poderemos garantir o direito de todas as crianças a uma educação de qualidade.

\section{Referências}

ABRAMOWICZ, Jaqueline (org.) Para além do fracasso escolar. Campinas, SP: Papirus, 1997. ALENCAR, E. M. L. S. Características sócio-emocionais do superdotado: questões atuais. Revista psicologia em estudo, Maringá, v. 12, n. 2, p. 371-378, maio/ago.2007.

BRANCHER, Vantoir Roberto e FREITAS, Soraia Napoleão de. Altas Habilidades/Superdotação: Conversas e Ensaios Acadêmicos/ Vantoir Roberto Brancher e Soraia Napoleão de Freitas. Jundiaí, Paco Editorial:

2011.

BRASIL. Constituição da República Federativa do Brasil. Brasília, DF: Senado Federal, 1988.

BRASIL. Projeto Escola Viva: Garantindo o Acesso e Permanência de Todos Alunos na Escola: Alunos com Necessidades Educacionais Especiais. Brasília: MEC, SEE, 2002 b.

Brasil. Secretaria de Educação Especial. Política nacional de educação especial: livro 1. Brasília: MEC/SEESP, 1994. 
(2001). Diretrizes Nacionais para a Educação Especial na Educação Básica Resolução $\mathrm{n}^{\circ} 02$ de 11 de setembro de 2001.

FREIRE, P. Pedagogia da autonomia: saberes necessários à prática educativa. São Paulo: Paz e Terra, 1999.

GARDNER, H. Estruturas da mente: a teoria das inteligências múltiplas. Porto Alegre: Artes Médicas, 1995.

GUENTHER, Z.C. Desenvolver capacidades e talentos: um conceito de inclusão. Petrópolis: Vozes, 2000.

LANDAU, E. A coragem de ser superdotado. Tradução de Sandra Miessa. São Paulo: CERED, 1990.

. Lei no 9.394, de 20 de dezembro de 1996. Lei Diretrizes e Bases da Educação Nacional. Brasília: Diário Oficial, nº 248, de 23/12/1996.

MANTOAN, M. T. E. (org.). Pensando e Fazendo Educação de Qualidade. São Paulo: Moderna, 2001.

Ministério da Educação (1995). Diretrizes gerais para o atendimento educacional aos alunos portadores de altas habilidades/superdotação e talentos. Brasília: Secretaria de Educação Especial.

MITTLER, Peter. Educação Inclusiva: Contextos Sociais. Edditota: Artmed, São Paulo, 2003.

RENZULLI, J.S. Os fatores da excepcionalidade, in Anais do XIV Congresso Mundial de Superdotação e Talento, Espanha: Barcelona, 2001.

SASSAKI, Romeu Kazumi. Inclusão: construindo uma sociedade para todos. $8^{a}$ Ed. Rio de Janeiro: WVA, 2010.

.Secretaria de Educação Especial. Subsídios para a organização e funcionamento de serviços de educação especial: Área de Altas Habilidades. Brasília: MEC/SEESP, 1995.

Secretaria de Educação Especial. Diretrizes gerais para o atendimento dos alunos portadores de altas habilidades, superdotação e talento. Brasília: MEC/SEESP, 1996.

.Secretaria de Educação Especial. Programa de capacitação de recursos humanos do ensino fundamental: superdotação e talento vols.1 e 2. Brasília: MEC/SEESP,1999.

UNESCO \& MEC-Espanha. Declaração de Salamanca e linha de ação. Brasília: CORDE, 1994.

WERNECK, Cláudia. Quem cabe no seu "Todos”? Rio de Janeiro: WVA, 1999.

\section{Como citar este artigo (Formato ABNT):}

SÁ, Paula Renata B.X. A Inclusão de Alunos com Altas Habilidades/Superdotação na Educação Básica: Um Desafio à Prática Pedagógica. Id on Line Revista Multidisciplinar e de Psicologia, 2017, vol.11, n.38, p. 480-492. ISSN: 1981-1179.

Recebido: 01.10.2017

Aceito: 03.11.2017 